\title{
Л.И. Шелепова
}

\section{ШУКШИНСКАЯ ЛЕКСИКОГРАФИЯ}

В статье представлена типология словарей (энциклопедических, лингвокультурологических, лингвистических), созданных на материале творчества В.М. Шукшина. Подробно освещаются история создания, проблемы и принципы составления «Словаря диалектизмов в произведениях В.М. Шукиина». Внимание автора сосредоточено на анализе словника данного лексикографического труда и зоне интерпретаџии значений объясняемьх слов. Показана необходимость при определении значений диалектных слов в языке писателя тщательного и всестороннего учёта контекста. Приведены примеры словарных статей.

Ключевые слова: творчество В.М. Шукиина, иукииноведение, лексикография, типология словарей, диалектизм.

$\mathcal{1}_{\text {вторская (писательская) лексикография относится к числу }}^{\text {ванений, активно развиваемых в современной словар- }}$ ной науке. На сегодняшний день определены основные периоды в истории авторской лексикографии, предложены типологии авторских словарей, выявлены черты их макроструктуры и микроструктуры [1].

Среди многочисленных словарей, созданных на материале произведений писателей, достойное место занимает шукшинская лексикография, анализу которой посвящена данная статья.

Перед исследователями творчества В.М. Шукшина неоднократно вставал вопрос о необходимости создания разноаспектных словарей языка писателя. Пожалуй, впервые поставила этот вопрос И.А. Воробьева, предложив в 1989 г. два проекта: ономастического словаря по произведениям В.М. Шукшина [2] и словаря языка В.М. Шукшина [3].

В настоящее время можно уже представить определенную типологию словарей, составленных на материале творчества В.М. Шукшина. Так, к словарям энциклопедического типа относятся: 1) издание «Творчество В.М. Шукшина: Энциклопедический словарь-справочник» (научный редактор А.А Чувакин), цель которого - «дать в систематизированном виде краткие сведения о творчестве B.М. Шукшина в целом и о литературно-художественном творчестве в частности, а также о филологическом шукшиноведении как формирующейся отрасли гуманитарного знания» [4. Т. 1. С. 8]; 2) «Шук- 
шинская энциклопедия» (главный редактор и составитель С.М. Козлова), ориентированная на массового читателя и посвященная (в связи с этим) главным образом описанию художественных произведений писателя [5]. К лингвокультурологическим словарям тяготеет «Словарь языка Василия Шукшина» В.С. Елистратова [6], в котором лексика произведений писателя объясняется в культурноисторическом контексте. Как лингвистические словари можно квалифицировать тематико-частотный словарь В.М. Шукшина, содержащий языковые единицы, репрезентирующие «человека телесного» в художественной прозе писателя, составленный И.Б. Ковалевой [7], а также толковые (объяснительные) словари: «Словарь фразеологизмов в произведениях В.М. Шукшина» А.Д. Соловьевой [8], «Словарь языка рассказов В.М. Шукшина» Т.Ф. Байрамовой и В.П. Никишаевой [9] и «Словарь диалектизмов в произведениях В.М. Шукшина», созданный И.А. Воробьевой [10].

Словарь И.А. Воробьевой, как один из первых опытов лексикографического описания языка В.М. Шукшина [11. С. 106-107], заслуживает самого пристального внимания. Интерес представляют история создания словаря, проблемы и принципы его составления, а также те трудности, с которыми встретились редакторы словаря при подготовке его к изданию.

Подготовку диалектного словаря по произведениям В.М. Шукшина И.А. Воробьева начала в рамках коллективной работы над энциклопедическим словарем-справочником «В.М. Шукшин. Жизнь и творчество». В 1997 г. (уже после смерти ученого) выходит из печати ее программное исследование «Региональная культура в лексике прозаических произведений В.М. Шукшина», явившееся частью коллективной монографии «Проза В.М. Шукшина как лингвокультурный феномен 60-70-х годов» [12]. Здесь (вслед за другими исследователями) И.А. Воробьева акцентирует внимание на том, что основой индивидуального стиля В.М. Шукшина несомненно выступает разговорно-обиходный язык. Причем в своем творчестве писатель опирался не только на разговорную стихию литературного языка, но и на просторечие и диалектную речь, которую он знал с детства, впитав ее, по собственному выражению, “с молоком матери”. И.А. Воробьева обращает внимание на тот факт, что В.М. Шукшин не только хорошо знал говор родного алтайского села Сростки, который в первую очередь и отразился в его произведениях, но и запи- 
сывал специально речь своих земляков. «Можно даже сказать, подчеркивает И.А. Воробьева, - что у него [Шукшина] был профессиональный интерес к народному языку, словарь которого он хотел составить: «Сибирский разговорный словарь... чудится мне, что Сибирь есть та самая кладовая, которую давно пора открыть и выгрести все добро и раздать» [12. С. 111]. В приведенном исследовании И.А. Воробьевой представлен анализ (в аспекте взаимоотношения языка и культуры) достаточно большого массива диалектных слов, выбранных из романа «Любавины».

В этом же (1997) году продолжается публикация материалов И.А. Воробьевой к диалектному словарю по произведениям B.М. Шукшина: в работе «Творчество В.М. Шукшина. Опыт энциклопедического словаря-справочника» представлены предисловие к словарю и словарные статьи на буквы А - Л, подготовленные к печати сыном И.А. Воробьевой А.В. Морозовым [13]. В межвузовском сборнике статей «Язык прозы В.М. Шукшина: Теория. Наблюдения. Лексикографическое описание», вышедшем в 2001 г. в издательстве Алтайского университета, напечатан еще один фрагмент словаря (буквы М - O) [14].

Преждевременный уход из жизни (1996 г.) не позволил И.А. Воробьевой завершить словарь. Он (по большей части) сохранился в черновых набросках и материалах. Поэтому при подготовке словаря к полному изданию редакторы (В.А. Чеснокова и Л.И. Шелепова) сочли необходимым провести следующую работу.

Пожалуй, самая главная трудность заключалась в том, что до сих пор не издано полное собрание сочинений В.М. Шукшина. И.А. Воробьева (судя по всему) собирала диалектный лексический материал, фиксируя его на карточках, из разных изданий В.М. Шукшина, не документируя их, а отмечая лишь названия произведений. При редактировании словаря решено было опереться на пятикнижное издание литературного наследия писателя, осуществленное в 19861991 гг. Алтайским книжным издательством [15-19]. Составителем, автором большинства комментариев и послесловия здесь выступил доктор филологических наук, профессор В.Ф. Горн. Ценность данного издания заключается в том, что оно составлено по первым публикациям В.М. Шукшина, а это дает представление об авторском тексте (так публиковал сам Шукшин), хотя не всегда соответствует хронологическому принципу расположения рассказов. Таким обра- 
зом, все контексты (иллюстративный материал), приведенные в словаре, документируются: в круглых скобках (как это было у И.А. Воробьевой) указывается название произведения, в квадратных (принцип, введенный редакторами) - книга и страница (по названному пятикнижному изданию).

В результате пословной проверки материалов, собранных И.А. Воробьевой, по указанному пятикнижному собранию произведений В.М. Шукшина, перепроверки по словарям (диалектным, современного русского языка) изменился отчасти словник словаря. В него были включены дополнительно более ста диалектных слов и выражений (например, батун, батунок, белковать, будылья, братовья, копьтья, курка, лесинка, логовинка, матря, оглоблина, отводина, сеструха, стеблина, не стой тебя, гвоздем лететь и др.). Часть слов по тем или иным причинам была выведена из состава словника. Так, некоторые диалектные слова, выписанные И.А. Воробьевой из разных изданий, оказались непредставленными в привлеченном для работы над словарем издании (в основном из романа «Любавины»), например: банить - «мыть горячей водой», баџкать - «ударять с силой, энергично бить по чему-либо», большак - «старший сын», варок «хлев для домашнего скота», выворотень «вывороченное дерево», взлобок - «пригорок, возвышенное место» и нек. др. Не были включены в словарь (при его редактировании) лексические единицы, содержащиеся в материалах И.А. Воробьевой, которые в словарях современного русского языка даются с пометами «разг.» или «прост.», т.е. не являются словами диалектными (локально ограниченными), например: навалом - «в большом количестве», неторопкий «медлительный, неторопливый», отбрехаться - «отделаться отговорками», похмелиться - «опохмелиться», прищучить - «поймать, захватить» и др. Хотя решить задачу разграничения просторечного и диалектного слова (в связи с весьма подвижными границами между данными лексическими пластами) не всегда представляется возможным.

Подчеркнем, что в своей основе словник остался таким, каким сформировала его И.А. Воробьева. В окончательной редакции в словаре представлено лексикографическое описание около 1000 диалектных слов (вместе с вариантами), встречающихся в произведениях В.М. Шукшина. Как было задумано И.А. Воробьевой, сюда, кроме собственно диалектных слов, вошло несколько жаргонизмов 
(главным образом из тюремного арго); замастырить, шалашовка, духарь и др., небольшая часть фразеологизмов, а также некоторые специфически шукшинские слова и выражения: глубинка - «сокровенное, тайное (о душе)», душа с перевивом - «о человеке непростом, себе на уме», красотень - «красота» и др. Предполагается, что B.M. Шукшин как тонкий знаток диалекта, как человек, знающий говор изнутри, мог создавать новые (производные) слова по моделям диалектного (и не только диалектного) словообразования, как часто поступают и диалектоносители, создавая в своей речи новые слова.

Самая трудная область в любом толковом словаре, а тем более в словаре языка писателя (разновидностью которого является и анализируемый словарь), это зона определения значения слова. Принцип, сформулированный в предисловии к словарю («как правило, в словарной статье даётся общее значение, определяемое по «Словарю русских говоров Алтая» и другим диалектным словарям»), последовательно реализуется только при толковании слов, отражающих быт и уклад крестьянского хозяйства, флору и фауну данной местности, особенности социальной среды и т.п. Например: заимка - «земельный участок, удаленный от населенного пункта, занятый одним хозяином, с жилыми и хозяйственными постройками на нем»; заплот «забор из толстых досок»; западня - «крышка погреба или подполья»; кержак - «старообрядец, старовер» и т.д. Во многих случаях определение значения слова требует тщательного и всестороннего учёта контекста. Приведем одну лишь иллюстрацию в подтверждение этого. В материалах И.А. Воробьёвой отмечается наречие навыверт. Такого слова, как показала проверка, нет ни в существующих диалектных словарях, ни в словарях современного русского языка (в том числе 17-томном). Значение слова в материалах И.А. Воробьёвой определено так: «То же, что нараскоряк». И приводится контекст из романа «Я пришел дать вам волю»: «Ну, эдак-то моя тёшша бегала, даже резвей! Ноги-то навыверт». Слова нараскоряк в словнике не оказалось. В современном же «Словаре русских народных говоров», выпускаемом ныне в Санкт-Петербурге в издательстве «Наука», отмечено нараскоряку - «о широко, неуклюже расставленных ногах» [20. С. 120]. Привлечение более широкого контекста из романа В.М. Шукшина («Ну, эдак-то моя тёшша бегала, даже резвей! Ноги-то навыверт <... Это у твоей навыверт-то были $<\ldots>$ А у моей $<\ldots>$ ровные были ножки ...») позволяет точнее опре- 
делить значение приведённого наречия навыверт - «о недостаточно прямых (ровных), т.е. кривых ногах».

Приведем некоторые примеры словарных статей из «Словаря диалектизмов в произведениях В.М. Шукшина».

АНАДыСЬ, нареч. (НАДыСЬ). Недавно, на днях. - $C$ Феклой анадысь зашли, посидели («Любавины») [16. С. 226]. Я одной тут надысь печку растопила, отсырели дровишки, хоть плачь («Любавины») [16. С. 233].

БАЗЛаНИТЬ, ю, ишь, несов., неперех. Сильно, громко кричать, ругаться. - Жена вам - скандал? - Не, она у меня не базланит («Печки-лавочки») [15. С. 77]. Она видит, дело плохо, давай базланить («Страдания молодого Ваганова») [18. С. 31].

БАСТЫРоК, рка, м. Жердь, толстая палка для укрепления сена на возу. - <..> может, запоздаем в деревню-то - стемнеет, поедем переулком, я и сброшу. Да и положила поверх бастырка здор-оовызй навильник («Из детских лет Ивана Попова») [17. С. 366].

ВЕСЕЛиНКА, и, ж. Весёлые огоньки в глазах. - Он говорил спокойно, в маленьких умньх глазах его мериала веселинка («Хозяин бани и огорода») [18. С. 195].

ВЕЧЕРяТЬ, яю, яешь, несов., неперех. Ужинать. - Когда стемнело, к Любавиным явились четверо: Кузьма, Федя Байкалов, Пронька Воронцов и Ганя Косых. Емельян Спиридоныч вечерял («Любавины») [16. С. 280]. Клавдя и девочки вечеряли («Сапожки») [18. C. 237].

ВСАДиТьСЯ ДО УШеЙ. Сильно обмануться, ошибиться. Страшно, Коля, - говорила мать. - С одним всадилась до ушей... Но тогда хоть молодая была - простительно... («Позови меня в даль светлую») [15. С. 95].

ВСТАТЬ (СТАТЬ) НА ДЫБоШКИ. Возмутиться, резко проявить несогласие, протест. - Но в договоре этот пункт не помечен, и плотники встали «на дыюошки»: прилавок - не наше дело! («Танцующий Шива») [18. С. 159]. Хотел дочь свою так назвать... но жена на дыбошки стала («Лёля Селезнёва с факультета журналистики») [16. С. 125].

ГЛяНУТЬСЯ, нусь, нешься, несов. Нравиться. - Tут народ разный. Если он к тебе: «Bbl, мол, мне глянетесь, то-сё, разрешите вас под ручку», вы его по руке: «Не лезь!» («Ваня, ты как здесь?!) [17. 
С. 212]. А что, он тебе не глянется? - Кто? - Кто-кто!.. Ну парень-то, который лез-то («Критики») [17. С 155].

КАЗАНоК, нка, м. Сустав пальца. - Федя казанком указательного пальияа неуверенно стукнул в дверь («Любавины») [16. С. 84]. <...> Сашка и Костя постучали в дверь, обитую дерматином. - Пообивают двери - все казанки посшибаешь об эти скобки <...> («Хахаль») [18. С. 22]. Постучал <...> казанком в дверь комнаты Bеры Сергеевны («Энергичные люди») [15. С. 380].

ЛОПОТиНА, Ы, ж. Верхняя одежда. - Пару коней я вам даю, две бороны, плуг... из лопотинь - само собой: тулупишко, пимы. шаровары («Любавины») [16. С. 215].

ПРяСЛО, а, ср. Изгородь из жердей или досок, положенных горизонтально между вбитыми в землю кольями. - Раза два нарвался на кобелей. Один перепугал насмерть: видно было - прыгнул через прясло, здоровенный, как телок < ...> («Любавины») [16. С. 30]. Егор спустился в логовину, остановился поодаль от прясла... («Любавины») [16. С. 271].

РяСНЫЙ, ая, ое. Обильный, крупный. - А одна баба у нас есть, смешная такая!.. Наткнулась на рясный куст и успевает в две руки, и успевает («Хахаль») [8. С. 30]. Торчмя торчат рясные початки желтые и красные - облепихи («Любавины») [17. С. 76]. Домой Чудик приехал, когда шел рясный парной дождик («Чудик») [17. C. 337].

СОСКОЧиТЬ С ЗАРуБКИ. Стать неуправляемым, выйти из норм поведения. - Вань, - предостерегающе сказала мать, зная про сына, что он ни с того ни с сего может соскочить с зарубки («Ванька Тепляшин») [18. С. 352].

ТоШНО МНеЧЕНЬКИ. Плохо мне. - Дочери повскакали из-за стола... Заахали, заохали. - Тошно мнеченьки! Батюшки мои!.. Да кому это? - Тебе, кому. - Тошно мнеченьки! - Клавдя села на кровать, кровать заскрипела... («Сапожки») [18. С. 238]. Тошно мнеченьки!.. Как же теперь? Грех ведь! («Любавины» [16. С. 166].

уРОСЛИВЫЙ, ая, ое. Капризный, упрямый. - Шах - он шах и есть: я ему одно, он другое: уросливый, кое-как уговорил («Я пришел дать вам волю») [19. С. 40].

Когда «Словарь диалектизмов в произведениях В.М. Шукшина» находился в издательстве, стало известно о выходе из печати работы 
В.С. Елистратова «Словарь языка Василия Шукшина» [6]. В аннотации отмечается, что словарь содержит около 1500 слов и 700 фразеологических единиц. В него вошли разговорно-просторечные, диалектные единицы, жаргонизмы, архаизмы, историзмы, а также шукшинские неологизмы, встречающиеся в опубликованных текстах писателя (включая драматургию, тексты сценариев, статьи, интервью, рабочие записи). Не проводя последовательного сравнения данного лексикографического труда со словарем И.А. Воробьевой, отметим лишь заметное несходство этих изданий в части толкования значений сибирских (алтайских) слов. Приведем в связи с этим один (достаточно курьезный) случай. В романе «Любавины» встречается глагол накуряться в контексте: «Надо знающего человека - по рекето. А то накуряемся на порогах». Это, как свидетельствуют наши полевые записи, достаточно распространенное слово на Алтае и означает оно - «накупаться, погружаясь в воду с головой» [21. С. 43]. В «Алеше Бесконвойном» употреблен однокорневой глагол курять - «погружать на некоторое время в воду, окунать» [22. С. 367] («Когда Алеша особенно заходился на полке <...> он курял голову прямо в эту ванну»). В словаре В.С. Елистратова приводится тот же контекст (из «Любавиных») и слово накуряться толкуется следующим образом (совершенно неадекватно): «Провести много времени в бездействии, не имея возможности выйти из затруднительного положения <...>. Вероятно, от «курить» (прост. «курять»); имеется в виду долго просидеть в вынужденных перекурах» [6. С. 194195].

Представленные словари свидетельствуют о том, что шукшиноведение в своем развитии достигло такого важного (зрелого) этапа, как лексикографическое описание творчества писателя. Однако лексикографическую работу по произведениям В.М. Шукшина нельзя считать завершённой, поскольку, как указывалось выше, «ещё не издано полное академическое собрание сочинений В.М. Шукшина. Многие тексты писателя <..> не опубликованы. Поэтому полной, завершенной картины языка В.М. Шукшина составить невозможно. В дальнейшем многое может быть дополнено и уточнено» [6. С. 4].

\section{Лumepamypa}

1. Шестакова Л.Л. Русская авторская лексикография: теория, история, современность: дис. ... д-ра филол. наук. - М., 2012. - 570 с. 
2. Воробьева И.А. Ономастический словарь по произведениям В.М. Шукшина // В.М. Шукшин: Жизнь и творчество: тез. докл. Всесоюз. науч.-практ. конф. - Барнаул, 1989. - С. 105-108.

3. Воробьева И.А. Словарь языка В.М. Шукшина // Лексикографический сборник. - Томск, 1989. - С. 21-32.

4. Творчество В.М. Шукшина: Энцикл. слов.-справ. / науч. ред. А.А. Чувакин. Барнаул: Изд-во Алт. ун-та, 2004-2007. - Т. 1-3.

5. Шукшинская энциклопедия / гл. ред. и сост. С.М. Козлова. - Барнаул: Изд. Дом «Барнаул», 2011. - 518 с.

6. Елистратов В.С. Словарь языка Василия Шукшина. - М.: Азбуковник: Русские словари, 2001. - 432 с.

7. Ковалева И.Б. «Человек телесный»: опыт тематико-частотного словаря языка В.М. Шукшина. - Уфа: Антаир, 2011. - 118 с.

8. Соловьева А.Д. Словарь фразеологизмов в произведениях В.М. Шукшина // Творчество В.М. Шукшина: энцикл. слов.-справ. Т. 1 / науч. ред. А.А. Чувакин. Барнаул, 2004. - С. 207-331.

9. Байрамова Т.Ф., Никишаева В.П. Словарь языка рассказов В.М. Шукшина. Бийск: НИЦ, БПГУ им. В.М. Шукшина, 2002-2005. - Вып. 1-3.

10 .Воробьева И.А. Словарь диалектизмов в произведениях В.М. Шукшина / отв. ред. Л.И. Шелепова. - Барнаул: Изд-во Алт. ун-та, 2002. - 110 с.

11. Шелепова Л.И. Лексикография на Алтае: обзор диалектных и ономастических словарей // Вопр. лексикографии. - 2012. - № 2. - С. 104-109.

12. Региональная культура в лексике прозаических произведений В.М. Шукшина // Проза В.М. Шукшина как лингвокультурный феномен 60-70-х годов. - Барнаул, 1997. - C. 105-148.

13. Воробьева И.А. Словарь диалектизмов в произведениях В.М. Шукшина // Творчество В.М. Шукшина: Опыт энциклопедического словаря-справочника. - Барнаул, 1997. - С. 160-194.

14. Воробьева И.А. Материалы к диалектному словарю по произведениям B.M. Шукшина // Язык прозы В.М. Шукшина: Теория. Наблюдения. Лексикографическое описание. - Барнаул, 2001. - С. 161-172.

15. Шукшин В.М. Киноповести. Повести / сост. и авт. Коммент. В.Ф. Горн. Барнаул: Алт. кн. изд-во, 1986. - 496 с.

16. Шукшин В.М. Любавины: роман. Кн. 1: Сельские жители: ранние рассказы / комментарии В.Ф. Горна. - Барнаул: Алт. кн. изд-во, 1987. - 464 с.

17. Шукшин В.М. Любавины: роман. Кн. 2: Рассказы / коммент. В.Ф. Горна. Барнаул: Алт. кн. изд-во, 1988. - 384 с.

18. Шукшин В.М. Рассказы / состав. и коммент. В.Ф. Горна. - Барнаул: Алт. кн. изд-во, 1989. -592 с.

19. Шукшин B.M. Я пришел дать вам волю: роман. Публицистика / общ. подгот. и послесл. В.Ф. Горна. - Барнаул: Алт. кн. изд-во, 1991. - 506 с.

20. Словарь русских народных говоров. - Вып. 20 (накучкать - негоразд) / гл. ред. Ф.П. Филин. - Л.: Наука, 1985. - 376 с.

21. Историко-этимологический словарь русских говоров Алтая. - Вып. 7: Н-O (набуривать - ощелмачить) / под ред. Л.И. Шелеповой. - Барнаул: Изд-во Алт. ун-та, 2013. $-395 \mathrm{c}$. 
22. Историко-этимологический словарь русских говоров Алтая. - Вып. 5: К (картузный - кьяман) / под ред. Л.И. Шелеповой. - Барнаул: Изд-во Алт. ун-та, 2011. -389 c.

\section{LEXICOGRAPHY OF SHUKSHIN.}

Journal of Lexicography, 2014, 2 (6), pp. 94-105.

Shelepova Lyudmila I., Altai State University (Barnaul, Russian Federation). E-mail: 1shelepova@yandex.ru

Keywords: V.M. Shukshin's works, studies of Shukshin, lexicography, dictionary typology, dialectism.

The article considers the dictionaries (encyclopedic, linguoculturological, linguistic) created on the basis of V.M. Shukshin's works. The author focuses on the analysis of the macrostructure and microstructure of one of the first experiments of this lexicographical direction - the Dictionary of Dialect Words in the Works of V.M. Shukshin by I.A. Vorobyova, the preparation of which began while working on the encyclopedic dictionary-reference book V.M. Shukshin. Life and Work. Early death (1996) did not allow I.A. Vorobyova to complete dictionary that mostly preserved in the drafts and materials. In its preparation for the publication the editors (V.A. Chesnokova and L.I. Shelepova) found it necessary to carry out the following work.

One of the main difficulties was the lack of the complete works of V.M. Shukshin. I.A. Vorobyova (apparently) was collecting dialectal lexical material, fixing it on cards from different editions of Shukshin's works without documenting them, only noting the titles. When editing the dictionary, a decision was made to rely on the five-volume edition of the literary heritage of the writer of 1986 - 1991 published by Altai Publishing House. The value of this edition is that it is made by the first publications of Shukshin, which gives an idea of the author's text.

As a result of the word by word verification of material collected by Vorobyova in the fivevolume collected works of Shukshin and in dictionaries (dialectal, modern Russian language) the word list of the dictionary partly changed. It included more than one hundred additional dialect words and expressions. Part of the words, for a reason, was excluded from the word list. For instance, words from the material of Vorobyova that are marked as colloquial or highly colloquial in the modern Russian language dictionaries were not included in the dictionary (when editing it), for they are not dialect words, i.e. they are not locally limited. A comprehensive and thorough account of the context allowed specifying a number of definitions.

The final version of the dictionary has approximately 1,000 dialect words of all types found in the works of V.M. Shukshin. But for dialect and colloquial dialect lexical units the dictionary includes several jargon words (mainly from prison slang), a small part of idioms, as well as some Shukshin's neologisms. It is assumed that V.M. Shukshin as a connoisseur of dialects, a man knowing the dialect from within, could create new (derived) words by dialect (and not only dialect) word formation patterns, just like dialect speakers often do in their speech, when creating new words.

The presented dictionaries indicate that Shukshin studies in their development have reached a mature stage of the lexicographic description of the writer's work. 


\section{References}

1. Shestakova L.L. Russkaya avtorskaya leksikografiya: teoriya, istoriya, sovremennost'. Dis. dokt. filol. nauk [Russian author lexicography: theory, history, modernity. Philology Dr. Diss.]. Moscow, 2012. 570 p.

2. Vorobyova I.A. [Onomastic dictionary by the works of V.M. Shukshin]. V.M. Shukshin. Zhizn' i tvorchestvo: tez. dokl. vses. nauch.-prakt. konf. [V.M. Shukshin. Life and Works: Abstracts of reports at the All-Union Scientific and Practical Conference]. Barnaul: Altai State University Publ., 1989, pp. 105-108. (In Russian).

3. Vorobyova I.A. Slovar' yazyka V.M. Shukshina [Dictionary of V.M. Shukshin's language]. In: Leksikograficheskiy sbornik [Lexicographic collection]. Tomsk, 1989, pp. 21-32.

4. Chuvakin A.A. (ed.) Tvorchestvo V.M. Shukshina: Entsiklopedicheskiy slovar'spravochnik [Works of V.M. Shukshin: Encyclopedic Dictionary-Reference Book]. Barnaul: Altai State University Publ., 2004-2007. Vols. 1-3.

5. Kozlova S.M. (ed.) Shukshinskaya entsiklopediya [Shukshin's Encyclopedia]. Barnaul: Izdatel'skiy Dom "Barnaul" Publ., 2011. 518 p.

6. Elistratov V.S. Slovar' yazyka Vasiliya Shukshina [Dictionary of Vasiliy Shukshin's language]. Moscow: Azbukovnik; Russkie slovari Publ., 2001. 432 p.

7. Kovaleva I.B. "Chelovek telesnyy": opyt tematiko-chastotnogo slovarya yazyka V.M. Shukshina ["Earthy man": the experience of the thematic-frequency dictionary of V.M. Shukshin's language]. Ufa: Antair Publ., 2011. 118 p.

8. Solov'eva A.D. Slovar' frazeologizmov $v$ proizvedeniyakh V.M. Shukshina [Dictionary of idioms in the works of V.M. Shukshin]. In: Chuvakin A.A. (ed.) Tvorchestvo V.M. Shukshina: Entsiklopedicheskiy slovar'-spravochnik [Works of V.M. Shukshin: Encyclopedic Dictionary-Reference Book]. Barnaul: Altai State University Publ., 2004. Vol. 1, pp. 207-331.

9. Bayramova T.F., Nikishaeva V.P. Slovar' yazyka rasskazov V.M. Shukshina [Dictionary of the language of V.M. Shukshin's stories]. Biysk: NITs, BPGU im. V.M. Shukshina Publ., 2002-2005. Issues 1-3.

10.Vorob'eva I.A. Slovar' dialektizmov v proizvedeniyakh V.M. Shukshina [Dictionary of dialect words in the works of V.M. Shukshin]. Barnaul: Altai State University Publ., 2002. $110 \mathrm{p}$.

11. Shelepova L.I. Lexicography in Altai: review of dialect and onomastic dictionaries. Voprosy leksikografii - Journal of Lexicography, 2012, no. 2, pp. 104-109. (In Russian).

12. Vorobyova I.A. Regional'naya kul'tura v leksike prozaicheskikh proizvedeniy V.M. Shukshina [Regional culture in V.M. Shukshin's prose works lexicon]. In: Pishchal'nikova V.A. (ed.) Proza V.M. Shukshina kak lingvokul'turnyy fenomen 60-70-kh godov [Prose of V.M. Shukshin as a linguocultural phenomenon of the $60 \mathrm{~s}-70 \mathrm{~s}]$. Barnaul: Altai State University Publ., 1997, pp. 105-148.

13. Vorobyova I.A. Slovar' dialektizmov v proizvedeniyakh V.M. Shukshina [Dictionary of Dialect Words in V.M. Shukshin's Works]. In: Chuvakin A.A. (ed.) Tvorchestvo V.M. Shukshina: Opyt entsiklopedicheskogo slovarya-spravochnika [Works of V.M. Shukshin: experience of an encyclopedic dictionary-reference book]. Barnaul: Altai State University Publ., 1997, pp. 160-194. 
14. Vorobyova I.A. Materialy $k$ dialektnomu slovaryu po proizvedeniyam V.M. Shukshina [Materials for the dialect dictionary by works of V.M. Shukshin]. In: Chuvakin A.A. (ed.) Yazyk prozy V.M. Shukshina: Teoriya. Nablyudeniya. Leksikograficheskoe opisanie [Language of V.M. Shukshin's prose. Theory. Observations. Lexicographic description]. Barnaul: Altai State University Publ., 2001, pp. 161-172.

15. Shukshin V.M. Kinopovesti. Povesti [Movie-essays. Stories]. Barnaul: Altayskoye knizhnoye izdatel'stvo Publ., 1986. 496 p.

16. Shukshin V.M. Lyubaviny: roman. Kniga pervaya. Sel'skie zhiteli: rannie rasskazy [Lyubaviny: a novel. Book One. Village Dwellers: early stories]. Barnaul: Altayskoye knizhnoye izdatel'stvo Publ., 1987. 464 p.

17. Shukshin V.M. Lyubaviny: roman. Kniga vtoraya. Rasskazy [Lyubaviny: a novel. Book Two. Stories]. Barnaul: Altayskoye knizhnoye izdatel'stvo Publ., 1988. 384 p.

18. Shukshin V.M. Rasskazy [Stories]. Barnaul: Altayskoye knizhnoye izdatel'stvo Publ., 1989. 592 p.

19. Shukshin V.M. Ya prishel dat' vam volyu: roman. Publitsistika [I Came to Give You Freedom: a novel. Journalism]. Barnaul: Altayskoye knizhnoye izdatel'stvo Publ., 1991. $506 \mathrm{p}$.

20. Filin F.P. (ed.) Slovar' russkikh narodnykh govorov [Dictionary of Russian Folk Dialects]. Leningrad: Nauka Publ., 1985. Issue 20, 376 p.

21. Shelepova L.I. (ed.) Istoriko-etimologicheskiy slovar' russkikh govorov Altaya [Historical and etymological dictionary of the Russian dialects of the Altai]. Barnaul: Altai State University Publ., 2013. Issue 7, 395 p.

22. Shelepova L.I. (ed.) Istoriko-etimologicheskiy slovar' russkikh govorov Altaya [Historical and etymological dictionary of the Russian dialects of the Altai]. Barnaul: Altai State University Publ., 2011. Issue 5, 389 p. 